\title{
Article
}

\section{Air Classification of Korean Natural Zeolite to Improve Adsorption of Ammonium Ion}

\author{
${ }^{*}$ Yujiro Watanabe ${ }^{1)}$, Hirohisa Yamada ${ }^{2)}$, Shingo Yokoyama ${ }^{3)}$, Junichi Minato ${ }^{4)}$, Yun-Jong Kim ${ }^{5)}$, \\ Sung Baek Cho ${ }^{6)}$, Kenji Tamura ${ }^{2)}$, Geoffrey W. Stevens ${ }^{7)}$ and Yu Komatsu ${ }^{1)}$ \\ ${ }^{1)}$ College of Environmental Engineering and Architecture, Kanazawa Institute of Technology, 7-1 Ohgigaoka, \\ Nonoichi, Ishikawa 921-8501, Japan \\ ${ }^{2)}$ Photocatalytic Materials Center, National Institute for Materials Science, 1-1 Namiki, Tsukuba, Ibaraki \\ 305-0044 Japan \\ ${ }^{3)}$ Civil Engineering Research Laboratory, Central Research Institute of Electric Power Industry, Abiko, Chiba \\ 270-1194 Japan \\ 4) Nippon Sheet Glass Co., Ltd.., 5-4 Tokodai, Tsukuba, Ibaraki 300-2635, Japan \\ ${ }^{5)}$ Department of Materials Engineering, Paichai University, 439-6, Doma-dong, Seo-gu, Daejeon 302-735, Korea \\ ${ }^{6)}$ Korea Institute of Geoscience \& Mineral Resources, 30, Gajeong-dong, Yuseong-gu, Daejeon 305-350 Korea \\ ${ }^{7)}$ Department of Chemical Engineering, The University of Melbourne, Parkville, Victoria 3010 Australia
}

(Manuscript submitted March 31, 2007; accepted April 28, 2007)

\begin{abstract}
Korean natural zeolite with feldspar and illite as impurities was purified by air classification to improve the ammonium adsorption capacities. The treated zeolite was classified into 5 fractions with different amounts of zeolite minerals and impurities. Ammonium adsorptions on the air-classified samples in ammonium chloride solution were compared with that of unclassified zeolite. The highest capacity for ammonium adsorption was obtained for the air-classified sample operated at $12000 \mathrm{rpm}$ with the largest amount of zeolite and the smallest amount of feldspar. The maximum adsorption capacity was $0.93 \mathrm{mmol} / \mathrm{g}$, which was 1.2 times the unclassified sample.
\end{abstract}

Key words: air classification, ammonium adsorption, Korean natural zeolite

\section{Introduction}

Natural zeolites are used as low-cost ion exchangers in various industrial applications.[1-4] Clinoptilolite and mordenite are the main minerals of natural zeolites found in abundance in many locations.[5] These minerals have three-dimensional open-framework structures consisting of $\mathrm{AlO}_{4}$ and $\mathrm{SiO}_{4}$ tetrahedra linked together by oxygen sharing and contain channels and cavities in which cations and water molecules can diffuse as well as ion-exchange sites. The chemical behavior of natural zeolites in aqueous solutions has been investigated.[6-8] The use of natural zeolites for removal of ammonium ion in wastewater treatment has been reviewed by a number of researchers. [8-12] The adsorption behavior of processed zeolite obtained by chemical and physical treatment has also been investigated.[13] The efficiency of the use of natural zeolite for removal of ammonium ions in wastewater depends on the zeolite species, the form of exchangeable cations,[10] and the 
amount of impurities.[8,14] As natural impurities such as feldspar reduces the capacity of ammonium adsorption, pretreatment is desired to remove them before use. In this study the ability of an air classification system to remove the impurities is presented. Air classification is an important process step to optimize product quality and classification of fine particles.[15] In an air classification system, particles are separated into fine and coarse fractions under the influence of airflow and inertial force such as gravity and centrifugal force. When the material consists of two or more constituents of different size, density, and hardness, purification is possible using air classification.

In the present study, air classification was applied to the natural zeolite from Pohang, southeast Korea to reduce the amount of impurities. Ammonium adsorption of the air-classified zeolites in ammonium chloride solution was compared with that of unclassified one. The results obtained were also compared with those published for other zeolites.

\section{Experimental}

\subsection{Materials}

Natural zeolite mined from Pohang, southeast Korea, was used in the present study. The zeolite consisted of clinoptilolite and mordenite, with feldspar and illite as impurities. The zeolite was powdered at first using a jaw crusher and a raymond mill, and then separated through a zigzag air classifier (HOSOKAWA-ALPINE Laboratory Classifier 100 MZR). The classifier consists of classifying wheel with 32 zigzag channels, wheel speed controller, classifying chamber and air blower. The classifier used in this investigation is a laboratory one for analytical or preparation separations which precisely separates powder particles with steplessly adjustable separating range of $2-80 \mu \mathrm{m}$. The powdered zeolite was separated into fine and coarse fraction with the desired wheel speed. The coarse fraction was then separated into the fine and the coarse fraction at a different rotational speed of classifier wheel. This procedure was repeated several times, and then the air-classified products operated at 4000,6000, 8000, 10000 and $12000 \mathrm{rpm}$ were obtained. The unclassified powdered zeolite, the air-classified products at 4000,6000, 8000, 10000, and $12000 \mathrm{rpm}$ were denoted to be $\mathrm{K} 00$, $\mathrm{K} 04, \mathrm{~K} 06, \mathrm{~K} 08$, $\mathrm{K} 10$, and $\mathrm{K} 12$, respectively.

\subsection{Characterization}

Mineral identification was carried out by the powder X-ray diffraction (XRD) with $\mathrm{CuK} \alpha$ radiation (RIGAKU RINT 2200). For the identification of layered silicate in the samples, the ethylene glycol treatment was performed according to Yamada et al.[16] The intercalation of ethylene glycol occurred for smectite, but not for illite.[17] The particle size distribution of the untreated and air-classified samples was measured by laser diffraction (HELOS \& RODOS Laser Diffraction Analyser, Sympatec GmbH, Clausthal-Zellerfeld). The chemical composition of the minerals was carried out grain by grain with energy dispersive X-ray (EDX) analysis (JEOL JED-2110 attached to scanning electron microscope (JEOL JSM-5800LV)) operated at $15 \mathrm{kV}$. The chemical compositions of the unclassified and air-classified products were determined by inductively coupled plasma spectroscopy (ICP, Nippon Jarrell-Ash IRIS Advantage). A photomultiplier tube was used as the detector for ICP. The solutions for ICP were prepared as follows: for $\mathrm{Si}, \mathrm{Al}, \mathrm{Ca}$, and $\mathrm{Mg}, 50 \mathrm{mg}$ of sample was mixed with $0.5 \mathrm{~g}$ of $\mathrm{Na}_{2} \mathrm{CO}_{3}$ and $0.2 \mathrm{~g}$ of $\mathrm{H}_{3} \mathrm{BO}_{3}$ powders. The mixture was dissolved by addition of $2.0 \mathrm{~mL}$ of $11.6 \mathrm{~mol} / \mathrm{L} \mathrm{HCl}$ solution, and pure water was added to the solution to a final volume of $100 \mathrm{~mL}$. For $\mathrm{Na}, \mathrm{K}$, and $\mathrm{Fe}, 30 \mathrm{mg}$ of sample was dissolved in $2.0 \mathrm{~mL}$ of $26 \mathrm{~mol} / \mathrm{L} \mathrm{HF}$ and $1 \mathrm{~mL}$ of $9 \mathrm{~mol} / \mathrm{L} \mathrm{H}_{2} \mathrm{SO}_{4}$ solutions. After the solution was evaporated, the dried residue was dissolved in $1.0 \mathrm{~mL}$ of $11.6 \mathrm{~mol} / \mathrm{L} \mathrm{HCl}$ solution with heating, and pure water was added to the solution to a final volume of $100 \mathrm{~mL}$. 


\subsection{Ammonium adsorption experiment}

For ammonium adsorption experiments, $30.0 \mathrm{~mL}$ of each solution containing different proportions of $\mathrm{NH}_{4} \mathrm{Cl}\left(10^{-3}-2 \times 10^{-2} \mathrm{~mol} / \mathrm{L}\right)$ was added to $0.1 \mathrm{~g}$ of air-dried samples in stoppered polypropylene tubes. The tubes were shaken by an end-over-end shaker (TOWA LABO RKVSD10101) at room temperature for 17 hours. The mixture was separated by centrifugation at $15000 \mathrm{rpm}$ for 15 minutes and then filtered with a $0.2 \mu \mathrm{m}$ membrane filter (FUJIFILM CASL-20). The ammonium concentration of the filtered solution was determined using an ammonium ion-specific electrode (TOA Electronics Ae-235) with the accuracy of more than $95 \%$.

\section{Results and Discussion}

\subsection{Characterization of untreared and air-classified zeolites}

Fig. 1 shows the XRD patterns of the samples before and after the air classification. All samples consisted mainly of clinoptilolite and mordenite with feldspar and trace of illite. Since no expansion to $17 \AA$ on glycol solvation was observed, the layered silicate in the sample was identified as illite. The relative peak intensities of clinoptilolite, mordenite, and feldspar except peaks

Table 1. Relative XRD peak intensities of minerals.

\begin{tabular}{lccc}
\hline & Clinoptilolite & Mordenite & Feldspar \\
\hline K12 & 128 & 136 & 39 \\
K10 & 126 & 140 & 42 \\
K08 & 97 & 126 & 83 \\
K06 & 84 & 103 & 155 \\
K04 & 59 & 88 & 199 \\
K00 & 100 & 100 & 100 \\
\hline
\end{tabular}

overlapped with those of the minerals in each sample were normalized to those of K00 (Table 1). The relative peak intensities of clinoptilolite and mordenite became weaker in the order of K12>K10>K08>K00>K06 $>$ $\mathrm{K} 04$, whereas that of feldspar became stronger in the reverse order of K12 $<\mathrm{K} 10<\mathrm{K} 08<\mathrm{K} 00<\mathrm{K} 06<\mathrm{K} 04$. These results indicate that the amount of clinoptilolite and mordenite increased and the amount of feldspar decreased as rotational speeds of classifier wheel increased. The particle size distributions of the samples were

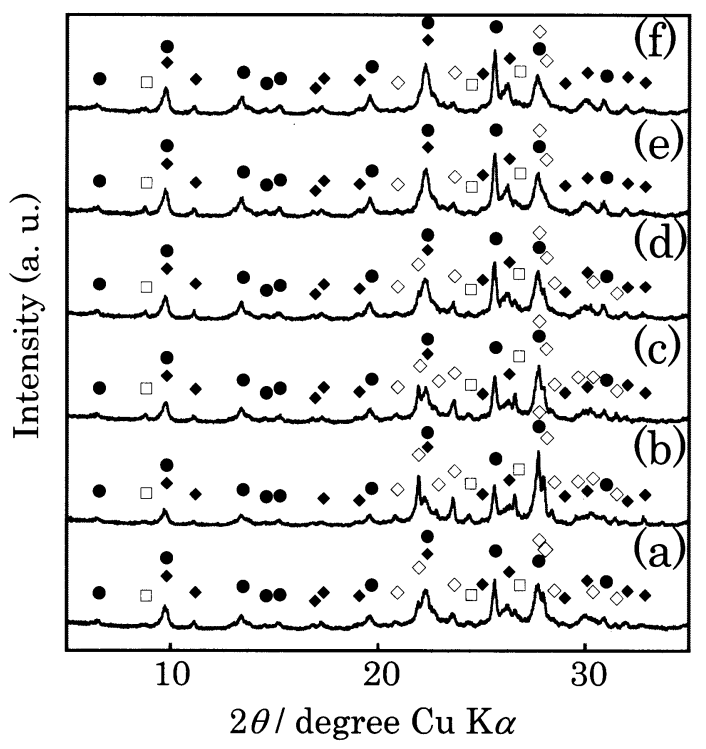

Fig. 1. X-ray diffraction patterns of (a) K00, (b) K04, (c) K06, (d) K08, (e) K10 and (f) K12. •: mordenite. $\bullet$ clinoptilolite. $\diamond$ : feldspar. $\square$ : illite.

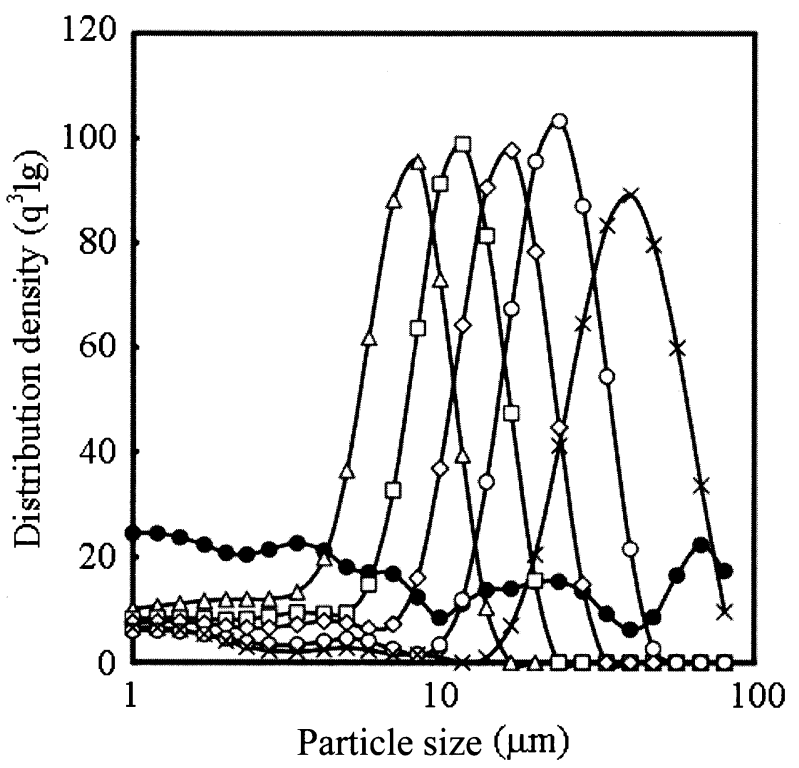

Fig. 2. Particle size distribution of K00 (•), K04 (×), $\mathrm{K} 06(\odot), \mathrm{K} 08(\diamond), \mathrm{K} 10(\square)$, and $\mathrm{K} 12(\Delta)$. 
measured by laser diffraction, as shown in Fig. 2. The particle size distributions of the air-classified samples were sharp. But the distribution of unclassified one was very broad and showed small several peaks. The average particle size of the air classified samples decreased systematically as the rotational speeds of classifier wheel increased; $6.3 \mu \mathrm{m}$, $9.4 \mu \mathrm{m}, 13.2 \mu \mathrm{m}, 20.6 \mu \mathrm{m}$ and 35.6 $\mu \mathrm{m}$ for the samples treated at 12000 rpm, $10000 \mathrm{rpm}, 8000 \mathrm{rpm}, 6000 \mathrm{rpm}$ and $4000 \mathrm{rpm}$, respectively. The zigzag air classification effectively made a precise separation. Because the hardness and specific density of constituent minerals in the sample were different, the separation of zeolites and impurities also should be performed. The speculation was consistent with those obtained by the above XRD results. The chemical compositions of minerals in untreated sample; clinoptilolite, mordenite, feldspar and illite are determined by EDX analysis (Table 2). These morphologies and chemical compositions corresponded with those of published studies.[7, 18,19] The $\mathrm{Si} / \mathrm{Al}$ mole ratios of clinoptilolite and mordenite are higher than those of feldspar and illite. The illite contains significant $\mathrm{Fe}$ and $\mathrm{Mg}$, and the feldspar richly contains significant $\mathrm{Na}$ as compared with clinoptilolite and mordenite. The chemical compositions of the samples before and after air classification determined by ICP are shown in Table 3. As the speeds of classifier wheel increased, the Si/Al mole ratio increased and the amounts of $\mathrm{Na}$ decreased systematically. These results indicate that the amounts of clinoptilolite and mordenite increased, and that of feldspar decreased after the air-classification. The amounts of Fe and Mg in their samples were almost constant before and after the air classification. XRD and chemical analyses of untreated and air-classified samples concluded that the present zigzag air classification was effective at reducing the amount of impurities, especially feldspar, of the Korean natural zeolite.

\subsection{Ammonium adsorption behavior}

The ammonium adsorption isotherms of the samples in ammonium chloride solution are shown in Fig. 3. The sample K12 showed the highest ammonium adsorption capacity among the samples, with a capacity of 0.93 $\mathrm{mmol} / \mathrm{g}$ in $10 \mathrm{mmol} / \mathrm{L} \mathrm{NH} \mathrm{NCl}_{4}$, which was 1.2 times as much as that of $\mathrm{K} 00$. Ammonium adsorption capacity decreased in the order of $\mathrm{K} 12>\mathrm{K} 10>\mathrm{K} 8>\mathrm{K} 00>\mathrm{K} 06>\mathrm{K} 04$. This order was observed to correspond to both decreasing amount of zeolites (clinoptilolite and mordenite) and increase of impurity (feldspar) in the samples with the decrease of wheel speed of classifier in the previous section. So this phenomenon can be explained by the difference in component percentages of minerals among the samples. K12 was identified to be sample with the largest amount of clinoptilolite and mordenite and with smallest amount of feldspar among the samples. The 
above order was also observed for the change of the particle size distribution of the air-classified samples (Fig. 2). Kang et al. compared the cation exchange capacities of Korean natural zeolite with different particle sizes by pulverizing and sieving.[20] They showed the magnitude of the measured cation exchange capacity was not significantly affected by the particle size. It is explained in most of the cation-exchange sites of zeolite exist in the pores and that the number of cation-exchange sites do not increase by pulverizing. The ammonium adsorption capacity of $\mathrm{K} 12$ is comparable to the high purity natural zeolite (clinoptilolite) from Shimane Prefecture, Japan.[8] K12 has similar but slightly higher exchange capacity than other previously reported zeolites.[1] The present results indicated that zigzag air classification was effective in improving ammonium adsorption of Korean natural zeolite as a direct result of the reduction of the amount of impurity, especially feldspar, from the natural zeolite. These results will be useful as a basic research for efficient removal of the ammonium ions from wastewater using natural zeolites.

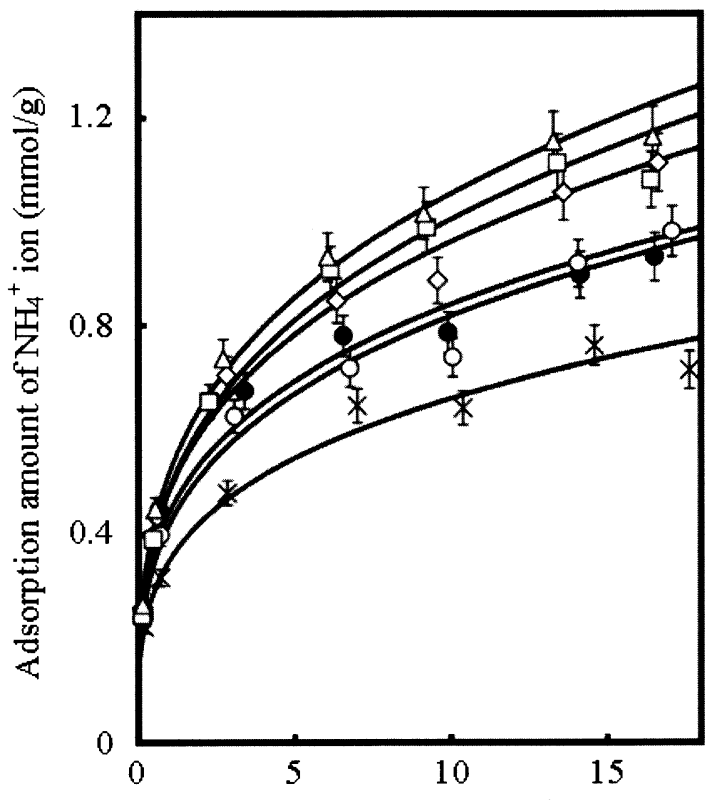

Equilibrium concentration of $\mathrm{NH}_{4}{ }^{+}$ion $(\mathrm{mmol} / \mathrm{l})$

Fig. 3. Ammonium adsorption isotherms of K00 $(\bullet), \mathrm{K} 04(\times), \mathrm{K} 06(\circ), \mathrm{K} 08(\diamond), \mathrm{K} 10(\square)$, and K12 $(\Delta)$.

\section{Acknowledgments}

The authors are grateful to Dr. T. Ishigaki and Mr. H. Tanaka, National Institute for Materials Science, for their help in particle size distribution measurement, and Mr. Y. Yajima, National Institute for Materials Science, for his help in ICP analysis.

\section{References}

1) F. A. Mumpton, "Natural Zeolites: Occurrence, Properties, Use" (Eds. L. B. Sand and F. A. Mumpton), Pergamon Press, New York (1978), pp. 3-27.

2) D. E. W. Vaughan, "Natural Zeolites: Occurrence, Properties, Use" (Eds. L. B. Sand and F. A. Mumpton), Pergamon Press, New York (1978), pp. 353-371.

3) K. Torii, "Natural Zeolites: Occurrence, Properties, Use" (Eds. L. B. Sand and F. A. Mumpton), Pergamon Press, New York (1978), pp. 441-450.

4) B. W. Mercer, L. L. Ames, "Natural Zeolites: Occurrence, Properties, Use” (Eds. L. B. Sand and F. A. Mumpton), Pergamon Press, New York (1978), pp. 451-462.

5) R. L. Hay, "Natural Zeolites: Occurrence, Properties, Use" (Eds. L. B. Sand and F. A. Mumpton), Pergamon Press, New York (1978), pp. 135-174.

6) C. Murphy, O. Hrycyk and W. T. Gleason, "Natural Zeolites: Occurrence, Properties, Use" (Eds. L. B. Sand and F. A. Mumpton), Pergamon Press, New York (1978), pp. 471-478.

7) D. W. Breck, “'Zeolite Molecular Sieves” Wiley, New York, (1974), pp. 498-507.

8) Y. Watanabe, H. Yamada, H. Kokusen, J. Tanaka, Y. Moriyoshi and Y. Komatsu, Separ. Sci. Technol. 38, 
1519-1532 (2003).

9) N. A. Booker, E. L. Cooney, and A. J. Priestley, Water Sci. Technol., 34, 17-24 (1996).

10) E. L. Cooney, N. A. Booker, D. C.Shallcross, and G. W. Stevens, Sep. Sci. Technol., 34, 2307-2327 (1999).

11) E. L. Cooney, N. A. Booker, D. C.Shallcross, and G. W. Stevens, Sep. Sci. Technol., 34, 2741-2760 (1999).

12) Y. Watanabe, Y. Moriyoshi, H. Yamada, J. Minato, M. Sekita, J. Tanaka, Y. komatsu, and G. W. Stevens, J. Ion Exchange, 14, 217-220 (2003).

13) Z. Hagiwara and M. Uchida, "Natural Zeolites: Occurrence, Properties, Use" (Eds. L. B. Sand and

F. A. Mumpton), Pergamon Press, New York (1978), pp. 463-470.

14) S. J. Kang and K. Wada, Appl. Clay Sci., 3, 281-290 (1998).

15) F. Kaiser, Z. S. Der, Chem. Ing. Tech., 35, 273-282 (1963).

16) H. Yamada, H. Nakazawa, K. Yoshioka and T. Fujita, Clay Miner., 26, 359-369 (1991).

17) G. W. Brindley, "Crystal Structures of Clay Minerals and their X-ray Identification” (Eds. G. W. Brindley and G. Brown), Mineralogical Society, London (1984), pp. 125-195.

18) P. H. Ribbe, "Feldspar Mineralogy" (Eds. P. H. Ribbe), Mineralogical Society of America, Washinton (1983), pp. 1-20.

19) J. Srodon and D. D. Eberl "Micas" (Eds. S. W. Bailey), Mineralogical Society of America, Washinton (1984), pp. 495-544.

20) S. J. Kang, K. Egashira and J. Choi, Nendokagaku 27, 27-31 (1987) (in Japanese with English abstract). 